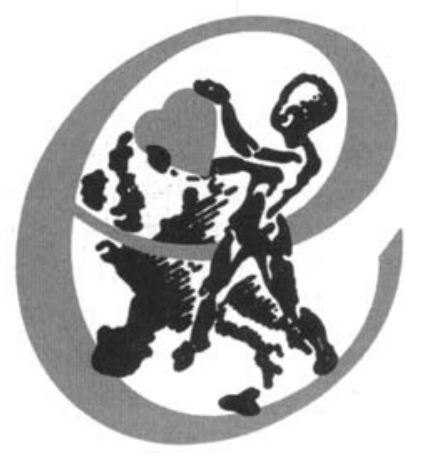

\title{
The Association for European Paediatric Cardiology prepares for the future
}

\author{
Fernando Maymone-Martins, Eric Silove, Otto Daniëls
}

$\mathrm{F}$ OR THE FIRST TIME IN THE PAGES OF Cardiology in the Young, we present News from the Association for European Paediatric Cardiology. The Association does not have an official journal. It appreciates, therefore, the initiative made by Cardiology in the Young in offering the forum with which to disseminate information relevant to Paediatric Cardiology in Europe. The timing could hardly be better! The Association has undergone a profound modernisation. For several years, many members of the Association had considered that the 30-year-old Constitution was in need of review. Accordingly, a Special Constitution Committee was appointed, with the specific task of preparing a revision designed to meet the challenge of advancing into the 21 st century. The resulting proposal was presented in August to the 32nd Annual General Meeting of the Association, held jointly in Stockholm with the 19th Congress of the European Society of Cardiology. The proposal of the Special Committee received the full support of the Council and, after discussion and some modification, it was approved by an overwhelming majority of the members. The main changes included:

- Change in membership, nature and name of the Association. The passage of time has made it clear that Paediatric Cardiology is not only the realm of Paediatric Cardiologists. There has always been co-operation with surgeons, with pathologists, and with specialists in other related fields. The new structure of the

Correpsondence to Dr O'Dantels, Secretary General AEPC, Childrenís Hear Centre, University Hospital Nijmegen, $6500 \mathrm{HB} \mathrm{N}_{1 j \mathrm{megen}}$ Netherlands $\mathrm{Tel}+31$ (24) $3619060, \quad \mathrm{Fax}+31$ (24) 36190 52. E-mal secra aepc org information on internet www aepc org
Association now provides for their admission as Ordinary members, as opposed to the Associate membership which was previously open to them. In consequence, the name of the Association has changed from "The Association of European Paediatric Cardiologists" to "The Association for European Paediatric Cardiology". In addition, its objectives have been modified from promoting "knowledge of diseases. . . up to adolescence" to the "knowledge of the normal and abnormal heart and circulation during growth and development". It has now also taken on the duty "to ensure a high standard of professional practice in paediatric cardiology in Europe".

- Opportunity for Junior membership. A new category of membership has now been created for those in training, and the new Junior members are to be represented on the Council. This measure should encourage our younger colleagues in their research and creativity.

- Professional interests. The Association has for some years provided guidelines for the training of paediatric cardiologists and for the requirements of training centres. ${ }^{1}$ A Board of National Delegates has now been established in order to ensure that all European Countries can have specific input to the Association. This is particularly relevant as harmonisation in professional affairs becomes increasingly necessary within the European Union. This modification also increases the strength of representation within the Association.

- The activities of the Working Groups and Board of National Delegates have been formally incorporated in the Constitution. These forums have existed for some years, and have made major contributions to the life and development of the 
Association. The Constitution now explicitly acknowledges their relevance, and the need for their participation.

Two Advisory Committees have been created to assist the Council: an Advisory Scientific Committee, including delegates from the Working Groups, and an Advisory Professional Committee, including National Delegates. These, as well as the Board of National Delegates and the Working Groups, will be ruled by specific bylaws discussed and approved at the Business Meetings of the Association. This will guarantee a framework for their activity, and yet still provide them with enough flexibility to adjust quickly to the needs posed by the admission of new professional categories without having to resort to further Constitutional changes.

The number and nature of the amendments summarised here virtually amount to a new Constitution. Their effects will first become evident at the 33rd Annual General Meeting due to take place next June in Dublin. They should result in significant changes in the life of the Association. Only experience will tell how fruitful these changes will be. The Association takes this opportunity to encourage all readers of Cardiology in the Young, not only those in Europe, to approach its Council with suggestions and proposals, in writing or in discussions, and to take the opportunity of playing an increased role in the activities and initiatives of the Association.

We expect, and hope, that all these changes, together with a more open forum, will be beneficial to the Association, to all those committed to the practice and advancement of Paediatric Cardiology, and especially to the patients who are the very reason of our professional activity.

\section{Structure of the Association}

The Association is governed by a Council. Two advisory committees support the Council: an Advisory Scientific Committee, in which Working Groups play an important role, and an Advisory Professional Committee, in which the Delegates representing 28 European countries make an important contribution.

Final decisions are made by the ordinary members in a General Assembly.

There are Working Groups for:

- Cardiovascular Morphology

- Congenital Heart Disease in Adolescents and Grown-Ups
- Fetal Cardiology

- Interventional Cardiology

- Genetics and Basic Sciences

- Cardiac Imaging

- Paediatric Cardiac Arrhythmias and Electrophysiology

- Psycho-Social aspects

\section{Present Council}

President: Prof. Fernando Maymone Martins

President-elect: Dr Eric Silove

Secretary-General :Dr Otto Daniëls

Scientific-Secretary: Prof. Marc Gewillig

Treasurer: Prof. Béat Friedli

Councillors: Prof. Christian Rey

Prof. Vladimir Pilossof

Prof. Helmut Singer

Prof. Erkki Pesonen

Chairman-elect: Dr. Desmond Duff

\section{Future Developments}

More attention will be given to the scientific work of the Working Groups. In the field of paediatric cardiology, where numbers of patients are small, multi-centric studies are particularly necessary. Moreover, the Working Groups are the forums for the exchange of ideas between scientists with similar interests. Combined studies incorporating centres from throughout Europe have been started, and some have been completed, such as the joint protocol for complete heart block in the fetus published as a combined study from Europe and the United States of America. ${ }^{2}$ A registry exists for collation of data concerning insertion of stents and closure of the arterial duct. A further collaborative venture concerns the treatment of supraventricular tachycardia in children. Other registries, such as one for hypoplastic left heart syndrome, are planned. In addition, the Working Groups are involved in postgraduate training and organisation of specialist courses.

In some countries, Paediatric Cardiology is already recognised as a monospecialty. We aim at achieving such recognition in the remaining European countries. Refinement of the requirements needed for training are in progress, and final proposals will come within one year. The means of standardising quality assessment, continuing medical education, and recertification are now under discussion. 


\section{Membership}

How to apply for membership? Information is given on the application forms, obtainable from the Secretary-General, which can also be printed from the home page of the Internet. New members may be Ordinary, Junior or Corresponding, the latter category offering membership to those who do not practise within Europe.

The annual subscription fee for Ordinary Members is 140 Swiss Francs, for Corresponding Members is 70 Swiss Francs and, for Junior Members, 50 Swiss Francs.
References

1. Daniels O, Choussat A. Paediatrıc Cardıology in Europe Medical/scientific statement of the Association of European Paedıatric Cardıologists: definition of profession and training requirements. Eur Heart J 1994, 15: 160-163

2 Fetal Cardıology Working Group of the Association of European Paediatric Cardıology Research protocols for fetuses with complete heart block. Ultrasound, Obstet Gynaecol 1995; 5, 349-352

\section{FUTURE AEPC CONGRESSES}

7th Symposium about Doppler Ultrasound in the Fetal Examination

Lech/Zug, Austria

March 29 - April 31998

Organizer: Dr G Tulzer

Phone: $+43(732) 69232346$

Fax: +43(732) 69232340

E-mail: g.tulzer@magnet.at

The 33rd Annual General Meeting of the Association of European Paediatric

\section{Cardiology}

Dublin, Ireland

June 10 - 13, 1998

Organizer: Desmond Duff

Our Ladies Chidren's Hospital

Dept Paediatric Cardiology

Crumlin

Dublin12

Ireland

Phone: +353 (1) 558111

Fax: +353 (1) 4558873

\section{Fetal Cardiovascular Systems}

Porto, Portugal

October $9-10,1998$

Organizer: Prof J.C. Areias

Hospital S. Joao

Dept of Paediatrics, Alaineda Hermani

Monteiro

4000 Porto

Portugal

Phone: +351 (2) 527151

Fax: + 351 (2) 525766
The 34th Annual General Meeting of the Association of European Paediatric

Cardiology

Sofia, Bulgaria

May 19-22 1999

Organizer: Vladimir Pilossoff

National Heart Centre

Dept of Paediatric Cardiology and Surgery

65. Miko Papo street

BG-1309 Sofia, Bulgaria

Phone: +359 (2) 221605

Fax: + 359 (2) 221605

E-mail: PCCS@SPS.BG

The 35rd Annual General Meeting of the Association of European Paediatric Cardiology

Strasbourg, France

May 31 -June 3, 2000

Organizer: Bernard De Geeter

Clinique Sainte Odile

Dépt. de Cardiologie Pédiatric

6 , rue Simonis

F-67100 Strasbourg

France

Phone: +33 (388) 404550

Fax: +33 (388) 404569

E-mail: drdegeeter@mail.sdv.fr 